\title{
Internet use patterns and the relation between generalized problematic internet use and psychological distress in Portuguese university students
}

\author{
Berta Rodrigues Maia ${ }^{1}$, Mariana Marques ${ }^{2,3}$, Ana Telma Pereira ${ }^{2}$ and António Macedo ${ }^{2,3}$ \\ ${ }^{1}$ Universidade Católica Portuguesa, Braga, Portugal \\ ${ }^{2}$ University of Coimbra, Coimbra, Portugal \\ ${ }^{3}$ Coimbra Hospital and University Centre, Coimbra, Portugal
}

\begin{abstract}
Internet use patterns, generalized problematic internet use, and the latter's relation to psychological distress were explored in a sample of 503 university students $\left(M_{\text {age }}=20.25 ; S D=2.75\right)$. A questionnaire about internet use patterns, the Generalized Problematic Internet Use Scale 2, and the Depression, Anxiety and Stress Scales were answered. The students spent 5 hours online on a daily basis. The total generalized problematic internet use index score corresponded to a medium-risk level, with $12.9 \%$ of men and $5.0 \%$ of women presenting a high-risk level. Higher total generalized problematic internet use risk levels corresponded to higher levels of depression, anxiety and stress. Our results seem to show that university students constitute a particularly vulnerable group in terms of problematic internet use, supporting the relation between generalized problematic internet use and psychological distress.
\end{abstract}

Keywords: Internet use patterns; generalized problematic internet use; psychological distress; university students.

Patrones de uso de internet, uso problemático generalizado de internet y su relación con el distrés psicológico en estudiantes universitarios portugueses

Resumen: Se exploraron los patrones de uso de internet, el uso problemático generalizado de internet y su relación con el distrés psicológico en una muestra de 503 estudiantes universitarios $(M$ edad $=20,25 ; D T=2.75)$, usando la Escala de Uso de Internet Problemático Generalizado 2 y las Escalas de Depresión, Ansiedad y Estrés. Los estudiantes pasan 5 horas diarias online. El índice total de uso problemático generalizado de internet corresponde a un riesgo medio, con un $12.9 \%$ de los hombres y un $5.0 \%$ de las mujeres presentando un nivel de riesgo alto. Los niveles superiores de riesgo de uso problemático generalizado de internet correspondieron a niveles superiores de depresión, ansiedad y estrés. Nuestros resultados parecen mostrar que los estudiantes universitarios constituyen un grupo particularmente vulnerable en cuanto al uso de internet y refuerzan la asociación entre el uso problemático generalizado de Internet y distrés psicológico.

Palabras clave: Patrones de uso de Internet; uso problemático generalizado de Internet; distrés psicológico; estudiantes universitarios.

\section{Introduction}

The internet has been one of the most important technological advancements in recent decades. Currently,

Recibido: 30 julio 2019; aceptado: 24 diciembre 2019

Corresponding author: Berta Rodrigues Maia, Universidade Católica Portuguesa, Faculdade de Filosofia e Ciências Sociais, Praça da Faculdade, 1, 4710-297, Braga, Portugal. E-mail: bmaia@braga.ucp.pt Acknowledgments: This study was carried out under the strategic project of the Centre for Philosophical and Humanistic Studies (CEFH) UID/FIL/00683/2019 funded by the Fundação para a Ciência e Tecnologia (FCT). approximately $40.0 \%$ of the world population has an internet connection (Internet Live Stats, 2019), in contrast with less than $1.0 \%$ in 1995 . Indeed, the number of internet users increased tenfold from 1999 to 2013. From 2000 to 2016 , the internet penetration rate ( $\%$ of population) increased from $6.8 \%$ to $46.1 \%$. In Europe, this rate was $85.2 \%$, and in Portugal, it was $77.9 \%$, corresponding to 8.015.519 internet users (Internet Live Stats, 2019). It can be said that although the rapid changes in technology are astounding and the widespread use of the internet has brought enormous opportunities and societal improvements, it has also given rise to new social issues. 
Research on the problematic use of the internet has grown at a very fast pace, with hundreds of studies already having been published on the topic. Furthermore, more than 20 psychometric measures/ instruments have been developed in this research area (Kuss, Griffiths, Karila, \& Billieux, 2014). Different conceptual and operational definitions of problematic internet use (PIU) have emerged: 'internet addiction' (e.g., Young, 1999), 'pathological internet use' (Morahan-Martin \& Schumacker, 2000), 'problematic internet use' (Caplan, 2002) and, more recently, 'compulsive internet use' (Meerkerk, Eijnden, Vermulst, \& Garretsen, 2009).

Although the benefits of the internet in our daily life are unquestionable, researchers have been investigating whether people are addicted to the internet itself or to specific internet activities (Starcevic, 2013). Researchers are also interested in exploring whether such addiction is an individual problem or if it might be the consequence of other pre-existing disorders (Tokunaga, 2015a). This question has led to a scientific debate as to whether internet addiction should be included as a separate disorder in the fifth edition of the Diagnostic and Statistical Manual of Mental Disorders (DSM-5; American Psychiatric Association, 2013). However, no agreement has yet been reached in the scientific community. Even so, in the DSM-5 (American Psychiatric Association, 2013) 'internet gambling disorder' was noted as a condition warranting future study, which was a major step towards the recognition of behavioural addictions as psychiatric disorders (Billieux, Schimmenti, Khazaal, Maurega, \& Heeren, 2015). More recently, the International Classification of Diseases and Related Health Problems (ICD-11; World Health Organization, 2019) included, for the first time, 'gaming disorder', comprising 'digital gaming' or 'video gaming' (which may occur online or offline), in the section on 'disorders due to addictive behaviors'.

Internet addiction is considered a problem that raises relevant social concerns (Vigna-Taglianti et al., 2017). Thus, internet use patterns are expressed along a continuum that runs from beneficial and positive use to negative extreme use, with deleterious consequences for the individual (Tokunaga, 2015b). Internet addiction is on the negative end of the continuum, leading to significant negative consequences (e.g., divorce, dropping out of school), while PIU is in the middle of the continuum, emphasizing the minor nature of its related negative outcomes, such as missing class (Tokunaga, 2015a). The cognitive behavioural perspective considers problematic internet use to be a pattern of internet-related cognitions, such as self- distortions or impaired self-control, and behaviours that result in deleterious life outcomes (Caplan, 2002). This perspective follows the diathesis-stress model according to which pre-existing psychosocial problems act as diatheses and life stressors as stress. In that sense, problematic internet use is the product of the relationship between psychosocial problems and stress.

Internet use in the university context is very common and has numerous benefits, such as its usefulness in academic research and for communication purposes. However, it can also lead to or be associated with several psychological problems, such as increased social anxiety (e.g., Weinstein, Doarni, Elhadif, Bukozva, \& Yarmulnik, 2015), sleep alteration and daytime sleepiness (e.g., Ferreira et al., 2017), and depression (e.g., Liang, Zhou, Yuan, Shao, \& Bian, 2016; Tokunaga \& Rains, 2016). Recent studies using samples of university students showed that PIU was significantly associated with anxiety, depression and stress (Gupta, Khan, Rajoura, \& Srivastsa, 2018; Odaci $\&$ Cokrilkci, 2017). Anxious students may use the internet as a coping mechanism, and depressive students may use the internet to avoid negative feelings (Gupta et al., 2018; Odaci \& Cokrilkci, 2017). Kuss and LopezFernandez (2016), in a systematic review of clinical research, point out that a possible explanation for the strong and common link between PIU and depression may be that as internet use grows, online activities take up increasingly more time in the lives of internet users. This might reduce the time available to engage in faceto-face relationships or other pleasant activities. This could, in turn, lead to higher feelings of solitude and stress (Poli \& Agrimi, 2012).

In Portugal, research about problematic internet use is rather new and still scarce. The majority of existing studies were conducted in samples composed of adolescents (e.g., Ferreira et al., 2017; Gamito et al., 2017; Patrão, Rita, \& Pontes, 2013; Pontes \& Griffiths, 2016; Pontes, Patrão, \& Griffiths 2014), and the vast majority used the Internet Addiction Test, which follows the disease model that is focused on diagnosis (Billieux et al., 2015). Following this trend, in the present study, in a sample of university students, we will explore problematic internet use and its relation to psychological distress (depression, anxiety and stress). Internet use patterns are also explored. Generalized internet use, the main focus of our study, refers to maladaptive cognitions and behaviours related to internet use that are not related to any particular content, such as online gambling. 


\section{Method}

\section{Participants}

The sample comprised 503 Portuguese university students, with a mean age of 20.19 years old $(S D=1.79$, age range: $18-25)$. The majority were women ( $n=399,79.8 \%)$ and single $(n=497,99.2 \%)$; many were attending their $1^{\text {st }}$ academic year $(n=196,40.8 \%)$ and most were from psychology $(n=170,39.5 \%)$, communication sciences $(n=86,20.0 \%)$ and medicine $(n=55,12.8 \%)$ courses.

\section{Measures}

The survey included questions related to sociodemographic characteristics, such as sex, age, course and academic year/level, and questions evaluating internet use patterns (e.g., daily time spent on the internet).

The Generalized Problematic Internet Use Scale-2 (GPIUS-2; Caplan, 2010; Portuguese version by Pontes, Caplan, \& Griffiths, 2016) is a multidimensional psychometric tool composed of 15 items that assesses the degree of generalized problematic internet use cognitions, behaviours, and negative outcomes experienced by individuals. The GPIUS2 is rated on a 7-point Likert scale (from $1=$ strongly disagree to $7=$ strongly agree). The scale factor structure in the Portuguese version evaluates problematic internet use, considering four constructs: preference for online social interaction, mood regulation, deficient self-regulation, and negative outcomes. This scale also allows the classification of the participants' potential risk of PIU using three latent classes: low (16.8), medium (34.1) and high (58.8) risk. Additionally, an overall GPIUS2 index score may be computed by summing all the items of the scale, with scores varying from 15 to 105 . Higher scores indicate a greater amount of generalized problematic internet use cognitions, behaviours, and negative outcomes. The Portuguese GPIUS2 demonstrated adequate validity and reliability, with Cronbach's alphas ranging from .78 (negative outcomes) to .86 (deficient self-regulation). In the present study, we found a Cronbach's alpha of .88 for the overall GPIUS2 index score, .67 for negative consequences and preference for online social interaction, .79 for mood regulation, and .86 for deficient self-regulation.

The Depression, Anxiety and Stress Scales (DASS21; Lovibond \& Lovibond, 1995; Portuguese version by Pais-Ribeiro, Honrado, \& Leal, 2004) is a self-report instrument composed of three subscales (depression, anxiety and stress) using a 4-point Likert scale ranging from 0 (does not apply to me at all) to 3 (applies to me very much or most of the time). Each scale is composed of seven items. Higher scores indicate higher negative emotional states, with scores varying from 0 to 21 . The Portuguese validation demonstrated adequate validity and reliability, with Cronbach's alpha ranging from .74 (anxiety) to .85 (depression). In the present study, we found a Cronbach's alpha of .86 for the depression subscale, .83 for the anxiety subscale, and .89 for the stress subscale.

\section{Procedures}

The current study was approved by the Ethical Commission of the Faculty of Medicine of the University of Coimbra, Portugal (ref. CE-026/2018). Data were collected at two universities in Portugal (one in the north and the other in the centre of the country) during the academic years of 2017/2018 and 2018/2019. The aims of the study were explained to the students before they were invited to participate. Written consent was obtained from all the participants, and confidentiality was assured. The students completed the measures in the classroom in the beginning of the second semester outside the evaluation period. The inclusion criteria were as follows: of Portuguese nationality and 18 to 25 years old.

\section{Data Analyses}

The data were analysed using SPSS, version 26. Descriptive statistics (frequencies, means and standard deviations) were computed for the study variables. A reliability analysis was performed to determine Cronbach's alpha coefficients. A $t$-test was conducted to explore the differences in the age of onset of internet use by sex. A chi-square test for independence, with Bonferroni adjustment for the alpha level, was conducted to explore associations between sex and the context of internet use and between sex and the number of social networks used by the participants. An independentsamples t-test was conducted to verify the differences in GPIUS2 index score by sex. Another chi-square test for independence was used to study the associations between GPIU risk levels and sex. To explore the differences in depression, anxiety and stress by GPIU risk levels, a one-way between-groups analysis of variance was conducted.

\section{Results}

\section{Internet use patterns}

The mean age of internet use onset was 11 years old $(S D=2.30$, range: 1-16). A one-way between-groups 
analysis of variance was conducted to explore the differences in the age of onset of internet use by sex, with no statistically significant associations being found: $F(1$, $491)=2.68, p=.102$. The majority of the students use the internet on the academic campus. A chi-square test for independence, with Bonferroni adjustment for the alpha level, indicated significant associations between sex and the context of internet use. Nearly $100 \%$ used the internet every day of the week. The students spent 5 hours online on a daily basis. For $33 \%$ of the participants, the time spent online frequently exceeded the time (of use) they planned to spend online. The majority of subjects preferred to be online during the night and, frequently, when alone. Statistically significant associations were also found between the variable "frequently online when alone/accompanied/or both" and sex, $\chi^{2}(2,496)=13.15$, $p=.001$, phi $=.16$. None of the other associations explored were statistically significant (see Table 1).
Nearly $100 \%$ of the students used social networks, and $75 \%$ of them had three or more social networks (range $=1$ to 7 ). A chi-square test for independence, with Bonferroni adjustment for the alpha level, indicated an association between sex and the number of social networks (that students have), with women having significantly more social networks than men. The social networks they reported using were Facebook, Instagram, Snapchat, Skype, Twitter, WhatsApp, and Viber. Only nine students reported using other additional social networks, such as LinkedIn, Pinterest, Quora, Reddit, 9gap, Tumblr, and YouTube. The majority usually shared content on social networks, with women sharing significantly more content, $\chi^{2}(1,490)=11.64, p=.001$, $p h i=-.15$. Most of them expressed feeling that in some way, the content to which they have access in the social networks influences their emotional state/disposition in a positive way. Additionally, $26 \%$ referred to feeling

Table 1. Internet use patterns (male and female sub-samples; total sample)

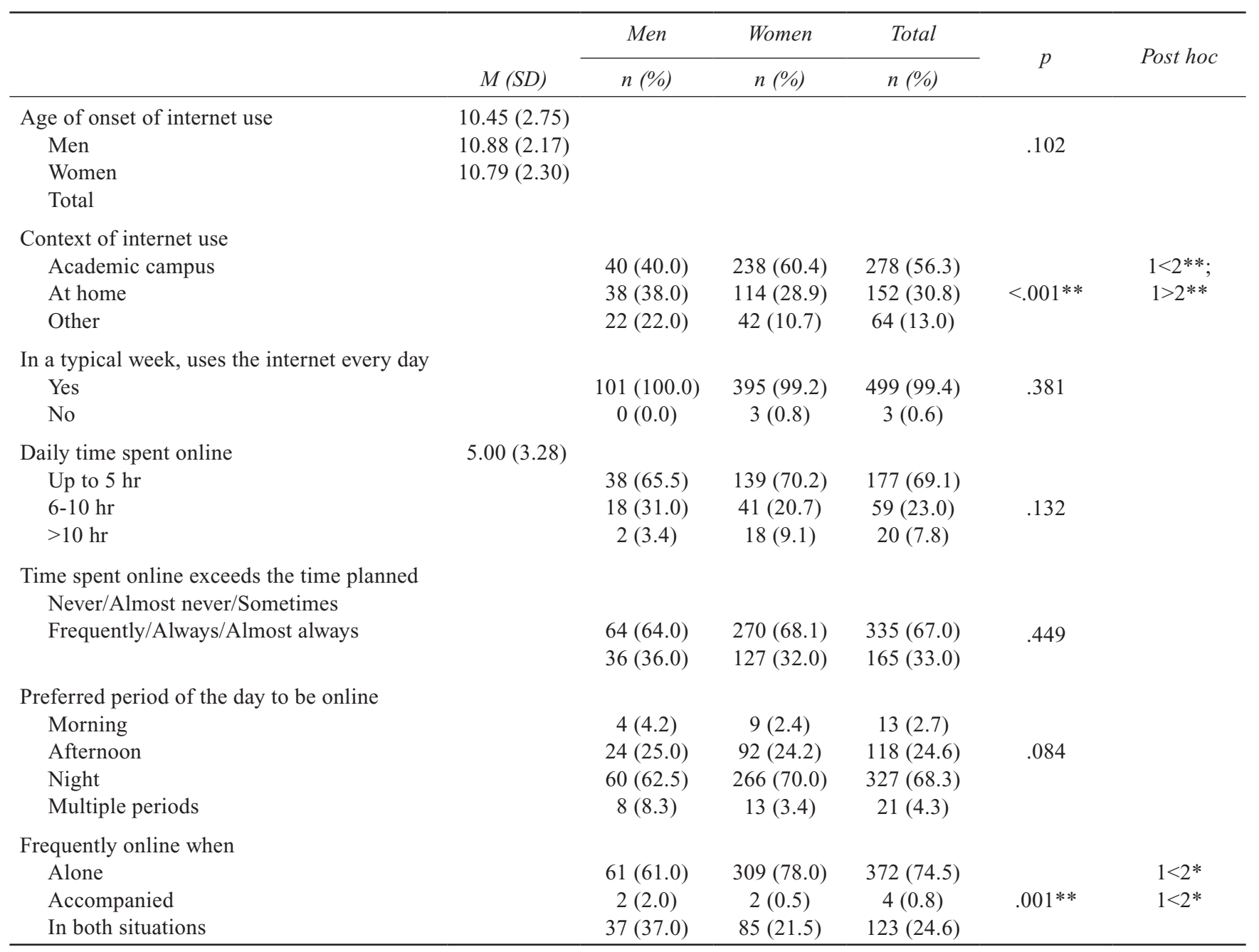

$* p<.05$, two-tailed. 
Table 2. Differences by sex in the use of social networks (and in its negative impact) and in internet parental control before university admission

\begin{tabular}{|c|c|c|c|c|c|}
\hline & \multirow{2}{*}{$\begin{array}{c}\text { Men } \\
n(\%)\end{array}$} & \multirow{2}{*}{$\begin{array}{c}\text { Women } \\
n(\%) \\
\end{array}$} & \multirow{2}{*}{$\begin{array}{l}\text { Total } \\
n(\%)\end{array}$} & \multirow{2}{*}{$p$} & \multirow{2}{*}{ Post hoc } \\
\hline & & & & & \\
\hline \multicolumn{6}{|l|}{ Social network use } \\
\hline Yes & $93(98.9)$ & $350(99.7)$ & $444(99.6)$ & .316 & \\
\hline No & $1(1.1)$ & $1(0.3)$ & $2(0.4)$ & & \\
\hline Number of social networks & & & $125(25.4)$ & & \\
\hline $1-2$ & $36(36.4)$ & $89(22.6)$ & $152(30.8)$ & & $1>2 *$ \\
\hline 3 & $29(29.3)$ & $123(31.2)$ & $216(43.8)$ & $<.014 * *$ & $1<2 *$ \\
\hline$>3$ & $34(34.3)$ & $182(46.2)$ & & & $1<2^{*}$ \\
\hline \multicolumn{6}{|c|}{ Usually shares content on social networks } \\
\hline Yes & $61(61.6)$ & $306(78.3)$ & $369(74.8)$ & $.001 * *$ & \\
\hline No & $38(38.4)$ & $85(21.7)$ & $124(25.2)$ & & \\
\hline \multicolumn{6}{|c|}{ Perceived emotional influence due to social network access } \\
\hline Positive influence & $50(50.0)$ & $228(58.8)$ & $215(76.2)$ & .115 & \\
\hline Negative influence & $50(50.0)$ & $160(41.2)$ & $67(23.8)$ & & \\
\hline \multicolumn{6}{|c|}{ Perceived negative impact of online activity on relationships } \\
\hline Yes & $43(43.0)$ & $86(21.8)$ & $129(25.9)$ & $<.001 * *$ & \\
\hline No & $57(57.0)$ & $309(78.2)$ & $369(74.1)$ & & \\
\hline \multicolumn{6}{|c|}{ Perceived negative impact of online activity on academic performance } \\
\hline Yes & $53(53.5)$ & $192(48.2)$ & $246(49.2)$ & .346 & \\
\hline No & $46(46.5)$ & $206(51.8)$ & $254(50.8)$ & & \\
\hline \multicolumn{6}{|c|}{ Internet parental control before university admission } \\
\hline Yes & $23(22.8)$ & $73(18.4)$ & $97(19.4)$ & .319 & \\
\hline No & $78(77.2)$ & $324(81.6)$ & $404(80.6)$ & & \\
\hline
\end{tabular}

$* p<.05$, two-tailed.

that their online activity undermines the quality of their relationships, with the perceived negative impact in relationships due to online activity being significantly higher in men $\left[\chi^{2}(1,495)=18.66, p=.001\right.$, $\left.p h i=.19\right]$ and $49 \%$ expressing interference in academic performance. Finally, $81 \%$ of the participants reported no parental control regarding internet use before entering university. All the other associations were not statistically significant (see Table 2).

\section{Generalized problematic internet levels and sex}

The total GPIUS2 index score was 35.37, equivalent to a medium risk. Considering GPIUS risk levels, $40 \%$ and $6.6 \%$ of the students presented a GPIU level corresponding to medium and high risk, respectively (Table 3).

An independent-samples t-test was conducted to compare the GPIUS2 index score by sex. There was no significant difference in scores between men $(M=36.86$, $S D=16.15)$ and women $[M=35.03, S D=13.23$; $t$ $(498)=1.19, p=.24$ (two-tailed)]. Moreover, a chi- square test for independence was used to explore GPIU risk levels by sex. Men presented significantly higher percentages of GPIUS low- and high-risk levels than women, and women presented significantly higher medium-risk level scores than men, $\chi^{2}(2, n=500)=9.83$, $p=.007$, Cramer's $V=.14$ (see Table 3).

\section{Differences in depression, anxiety and stress by GPIU risk levels}

To explore the differences in depression, anxiety and stress scores by GPIU risk level, a one-way betweengroups analysis of variance was conducted, with statistically significant differences $(\mathrm{p}<.05)$ being found: the higher the GPIU risk level, the higher the levels of depression, anxiety and stress. Post hoc comparisons using the Tukey HSD test indicated that the depression, anxiety and stress scores of the low GPIU risk group were significantly different from the same scores of the medium risk and high risk GPIU groups and that mean depression, anxiety and stress scores of the medium GPIU risk group were significantly higher than the same 
Table 3. Generalized problematic internet use levels (total sample and sub-samples)

\begin{tabular}{lcccc}
\hline & Total & Total & Men & Women \\
\cline { 2 - 5 } & $M(S D)$ & $n(\%)$ & $n(\%)$ & $n(\%)$ \\
\hline Preference for Online Social Interaction & $5.40(3.27)$ & & & \\
Mood Regulation & $10.18(4.84)$ & & & \\
Deficient Self-Regulation & $14.83(7.29)$ & & & \\
Negative Outcomes & $4.96(2.57)$ & & & \\
GPIU Index Score & $35.37(13.85)$ & & & \\
GPIU Low Risk & & $269(53.5)$ & $56(55.4)$ & $211(52.9)$ \\
GPIU Medium Risk & & $201(40.0)$ & $32(31.7)$ & $168(42.1)$ \\
GPIU High Risk & & $33(6.6)$ & $13(12.9)$ & $20(5.0)$ \\
\hline
\end{tabular}

Note. GPIU: Generalized problematic internet use

Table 4. Psychological distress by GPIU risk levels

\begin{tabular}{lcccccc}
\hline & $\begin{array}{c}\text { Low risk } \\
M(S D)\end{array}$ & $\begin{array}{c}\text { Medium risk } \\
M(S D)\end{array}$ & $\begin{array}{c}\text { High risk } \\
M(S D)\end{array}$ & $f$ & $p$ & Multiple comparisons \\
\hline Depression & $2.25(3.04)$ & $3.94(3.97)$ & $5.59(5.00)$ & 20.298 & $<.001$ & $1<2^{*}, 3^{*}, 2^{>}>1^{*},<3^{*} ; 3^{*} 1^{*}, 2^{*}$ \\
Anxiety & $2.17(2.93)$ & $3.46(3.79)$ & $5.09(3.46)$ & 15.957 & $<.001$ & $1<2^{*}, 3^{*}, 2>1^{*},<3^{*} ; 3>1^{*}, 2^{*}$ \\
Stress & $4.24(3.95)$ & $6.43(4.76)$ & $8.97(4.60)$ & 25.207 & $<.001$ & $1<2^{*}, 3^{*}, 2>1^{*},<3^{*} ; 3>1^{*}, 2^{*}$ \\
\hline
\end{tabular}

Note. GPIU: Generalized problematic internet use; $1=$ Low risk; $2=$ Medium risk; $3=$ High risk; ${ }^{*} p<.05$, two-tailed.

scores of the low GPIU risk group (and lower than the high GPIU risk group). Finally, the three mean scale scores of the high GPIU risk group were significantly higher than the mean scale scores of the medium and low GPIU risk groups. Despite reaching statistical significance, the differences in depression, anxiety and stress mean scores between groups were quite small. The effect sizes, calculated using eta squared, were 0.08 , 0.06 , and 0.09 , respectively. Post hoc comparisons using the Tukey HSD are presented in Table 4.

\section{Discussion}

The main aims of the present study were to explore internet use patterns and generalized problematic internet use and the latter's relation to psychological distress in a sample of Portuguese university students. To achieve these goals, we used a questionnaire assessing internet use patterns and two other validated measures, with good to very good psychometric properties. GPIUS2 was used, instead of the Addiction Internet Test (IAT), which has also been validated for Portugal, as we prefer to use the term 'problematic internet use', instead of 'internet addiction'. The former is a more wide-ranging term, covering the full range of problematic behavioursfrom mild to severe behaviours (Ang, Chong, Chye, \& Huan, 2012). Additionally, GPIUS2, unlike IAT, focuses on online activities exclusively related to leisure and not related to academic or occupational purposes.

In our sample, the mean age of internet first use was 11 years old. In a previous Portuguese study using an adolescent sample, the mean age found was 6 years old (Ferreira et al., 2017). In another Portuguese study (Pontes et al., 2016) comprising a sample from children to older adults (mean age $=25$ years; range $10-74$ years), the mean age of internet use initiation was 15 years old. This difference can be explained by the generational gap. Baby boomers have different internet habits than subsequent generations, such as Generation Y (born from 1980 to the end of the decade of 1990), which grew up with digital technology, and Generation Z (born between the 1990s and the beginning of the 2010s), composed of individuals who are considered digital natives. Thus, future research using cohort study designs is needed. It 
might also be important to explore whether the age of internet use initiation predicts negative consequences in the future and a worse prognosis in individuals with higher risk levels for generalized problematic internet use.

As expected, the majority of the students used the internet on the academic campus since they have free access to the internet in that context, and significant associations were found between this variable (context of internet use) and sex, with a higher percentage of women using the internet on the academic campus than men. The use of the internet in this context can also be related to the large periods of free time students have (while being on campus), as well as to higher expectations about the internet positive outcomes (Kandell, 1998). We found that women are connected to more social networks and, for that reason the time they spend online on the campus might also explain this result. FernandezVilla et al. (2015) reported that problematic internet use in men is related to aspects of entertainment, such as games or online shopping, and that in women is more related to aspects of socialization, such as chatting and social networks. These different interests might explain women's higher internet access levels on the academic campus and men's higher levels of access at home.

We verified that the students spent 5 hours a day online, which seems to be in accordance with a previous Portuguese study, conducted by Pontes et al. (2016), with a sample with a mean age of 25 years (age range $=10-74$ ). Additionally, for $33.0 \%$ of the individuals, the time spent online almost always exceeded the time they planned to spend online. Moreover, the frequent academic tasks requiring online searches can also explain the internet access on campus, as well the daily hours spent online. Subsequent studies should explore whether there is a significant negative impact (in different life aspects) for those who exceed the amount of time planned for internet use.

The majority of the students preferred to be online at night, revealing that they also had access to the internet at home, which confirms the growing ubiquity of the internet. Additionally, this use, especially among women, is more frequent when they are alone. Therefore, it is important to explore their social and free-time habits. Furthermore, $80.6 \%$ reported no parental control of internet use before entering university. Similarly low rates of internet parental control were reported in other recent European studies (e.g., Vigna-Taglianti et al., 2017). The absence of parental control of the use of the internet prior to university admission for most of the students is worrisome. The lack of parental monitoring places the responsibility for making secure choices with the child or adolescent at a developmental stage in which they do not have the maturity to make these types of decisions. Additionally, this lack of control can also potentiate other problems, such as sleep dysregulation.

Almost all of the students use social networks on a regular basis. The content to which they have access on the social networks influences their emotional state/ disposition, undermines the quality of their relationships and interferes with their academic performance. The perceived negative impact of online activity in relationships was significantly higher in men. Tokunaga (2015a) also found that PIU predicted difficulties in relationships (with family, friends) and in the occupational domain - academic and occupational responsibilitiesafter controlling for underlying factors, such as social anxiety, loneliness, and depression. In a longitudinal study, Tokunaga (2015a) found that freshmen university students were a particularly vulnerable group, since they have to deal with several adjustments that can initiate or activate pre-existing vulnerabilities.

Concerning GPIU levels, we found a total GPIUS2 index score of 35.37 , corresponding to a medium risk level (Pontes et al., 2016), and 6.6\% of the sample presented a GPIU high risk level. A slightly higher rate of GPIU was reported in a previous study (Laconi, Andréoletti, Chauchard, Rodgers, \& Chabrol, 2016). In a subsequent study, in high school students, the prevalence of PIU was $14.2 \%$ among men and $10.1 \%$ among women (VignaTaglianti et al., 2017). Vondrácková and Gabrhelík (2016), in their systematic review, considered studies using representative general population samples and reported that prevalence rates of problematic internet use ranged from $1 \%$ in Germany (Rumpft et al., 2014) to $3.4 \%$ in the Czech Republic (Smahel, Vondrácková, Blinka, \& Godoy-Etcheverry, 2009). However, considering other studies, this rate can vary among university students between $4.0 \%$ (e.g., Christakis, Moreno, Jelenchick, Myaing, \& Zhou, 2011) and $39.1 \%$ (Hawi, 2012). The amplitude of values seems to be related to several factors: socio-demographic aspects and the use of different methods and different assessment tools (e.g., Mihajlov \& Vejmelka, 2017).

In this study, men had a significantly higher percentage of high GPIU risk levels. Kamal (2018) also found significantly higher PIU levels in men than women (120.3 \pm 30.5 and $117.5 \pm 30.6$, respectively) in a sample of university students. Similar results were also found in other recent studies (e.g., Balalola, Ekundayo, AgioubuKemmer, \& Ayenibiowo, 2017).

Finally, we found significantly different levels of depression, anxiety and stress in the three GPIU risk groups. The higher the GPIU level, the higher the levels of 
depression, anxiety and stress. This finding corroborates the relation between GPIU and psychological distress. A similar result was found in previous studies (e.g., GámezGuadix, 2014; van den Eijenden, Meerkerk, Vermulst, Spijkerman, \& Engels, 2008). Problematic patterns of internet use frequently emerge when individuals want to regulate their negative emotional states (Kuss et al., 2017). However, the differences in depression, anxiety and stress mean scores between groups were small (considering the effect size). In that sense, our results, despite being statistically significant, should be interpreted carefully, and future studies are needed to clarify their relevance (e.g., clinical relevance).

The current study contributes to a better understanding of internet use patterns and of GPIU and its relation to sex and psychological distress. However, some limitations should be addressed. We used a convenience sample in a cross-sectional study, which does not allow the determination of causal relationships or the generalization of our results. Nevertheless, our inclusion criteria were an advantage, since we focused exclusively on students from 18 to 25 years old (instead of a mixed-age sample). Additionally, since we were interested in assessing the way internet use patterns relates to emotional states (depression, anxiety and stress), we believe that this study has the strength of controlling for the impact of stress associated with evaluation periods, since the questionnaires were answered outside these periods.

In sum, our results regarding the GPIUS2 index mean score and the association found between higher risk levels and higher psychological distress seem to show that university students constitute a group that is particularly vulnerable to problematic internet use and corroborate the relation between generalized problematic internet use and psychological distress.

\section{Conflict of interest}

The authors have no conflicts of interest to declare.

\section{References}

American Psychiatric Association (2013). Diagnostic and Statistical Manual of Mental Disorders (5th ed.). Arlington, VA: Author.

Ang, R. P., Chong, W. H., Chye, S., \& Huan, V. S. (2012). Loneliness and generalized problematic internet use: Parents' perceived knowledge of adolescents' online activities as a moderator. Computers in Human Behavior, 28(4), 1342-1347. doi: 10.1016/j.chb.2012.02.019

Balalola, O. B., Ekundayo, O. O., Agioubu-Kemmer, I., \& Ayenibiowo, K. O. (2017). Influence of sex and time spent online on Internet addiction among adolescents and youths in
South Western, Nigeria. Life Sciences Review, 25, 64-73. Retrieved from https://www.academia.edu/37324572/

Billieux, J., Schimmenti, A., Khazaal, Y., Maurage, P., \& Heeren, A. (2015). Are we overpathologizing everyday life? A tenable blueprint for behavioral addiction research. Journal of Behavioral Addictions, 4(3), 119-123. doi: 10.1556/2006.4.2015.009

Caplan, S. E. (2002). Problematic internet use and psychosocial well-being: Development of a theory-based cognitive-behavioral measurement instrument. Computers in Human Behavior, 18(5), 553-575. doi:10.1016/S0747-5632(02)00004-3

Caplan, S. E. (2010). Theory and measurement of generalized problematic internet use: A two-step approach. Computers in Human Behavior, 26(5), 1089-1097. doi:10.1016/j. chb.2010.03.012

Christakis, D. A., Moreno, M. M., Jelenchick, L., Myaing, M. T., \& Zhou, C. (2011). Problematic internet usage in US university students: A pilot study. BMC Medicine, 11, e77. doi:10.1186/1741-7015-9-77

Fernández-Villa, T., Ojeda, A. J., Gómez, A. A., Carral, J. M. C., Delgado-Rodríguez, M., García-Martín, ... Martín, V. (2015). Problematic internet use in university students: Associated factors and differences of gender. Adicciones, 27(4), 265-275. doi:10.1186/s12889-015-2281-5. Retrieved from http://www. adicciones.es/index.php/adicciones/article/view/751/721

Ferreira, C., Ferreira, H., Vieira, M. J., Costeira, M., Branco, L., Dias, A., \& Macedo, L. (2017). Epidemiology of Internet use by an adolescent population and its relation with sleep habits. Acta Médica Portuguesa, 30(7-8), 524-533. doi: 10.20344/ amp. 8205

Gámez-Guadix, M. (2014). Depressive symptoms and problematic internet use among adolescentes: Analysis of the longitudinal relationships from the cognitive-behavioral model. Cyberpsychology, Behavior and Social Networking, 17(11), 714-719. doi: 10.1089/cyber.2014.0226

Gamito, P. S., Morais, D. G., Oliveira, J. G., Brito, R., Rosa, P. J., \& Matos, M. G. (2017). Frequency is not enough: Patterns of use associated with risk of internet addiction in Portuguese adolescents. Computers in Human Behavior, 58, 471-478. doi: 10.1016/j.chb.2016.01.013

Gupta, A., Khan, A. M., Rajoura, O. P., \& Srivastsa, S. (2018). Internet addiction and its mental health correlates among undergraduate college students of a university in North India. Journal of Family and Medical Primary Care, 7(4), 721-727. doi: $10.4103 /$ jfmpc_266_17

Hawi, N. S. (2012). Internet addiction among adolescents in Lebanon. Computers in Human Behavior, 28(3), 1044-1053. doi: 10.1016/j.chb.2012.01.007

Kandell, J. (1998). Internet addiction on campus: The vulnerability of college students. Cyberpsychology \& Behavior, 1(1), 1117. doi:10.1089/cpb.1998.1.11

Kuss, D. J., Griffiths, M. D., Karila, L., \& Billieux, J. (2014). Internet addiction: A systematic review of epidemiological research for the last decade. Current Pharmaceutical Design, 20(25), 4026-4042. doi: 10.2174/13816128113199990617

Kuss, D. J., Dunn, T. J., Wolfling, K., Muller, K. W., Hedzelek, M., \& Marcinkowski, J. (2017). Excessive internet use and psychopathology: The role of coping. Clinical Neuropsychiatry: Journal of Treatment Evaluation, 14(1), 73- 
81. Retrieved from http://irep.ntu.ac.uk/id/eprint/28364/1/ PubSub5893A_Kuss.pdf

Kuss, D. J., \& Lopez-Fernandez-O. (2016). Internet addiction and problematic internet use: A systematic review of clinical research. Would Journal of Psychiatry, 6(1), 143-176. doi:10.5498/wjp.v6.i1.143

Laconi, S., Andréoletti, A., Chauchard, E., Rodgers, R. F., \& Chabrol, H. (2016). Problematic internet use, time spent online and personality traits. Encéphale, 42, 214-218. doi: 10.1016/j.encep. 2015.12.017

Liang, L., Zhou, D., Yuan, C., Shao, A., \& BIan, Y. (2016). Sex differences in the relationship between internet addiction and depression: A cross-lagged study in Chinese adolescents. Computers in Human Behavior, 63, 463-470. doi:10.1016/j. chb.2016.04.043

Lovibond, P., \& Lovibond, S. (1995). The structure of negative emotional states: Comparison of the depression anxiety stress scales (DASS) with the Beck Depression and Anxiety Inventories. Behaviour, Research and Therapy, 33(3), 335343. doi: 10-1016/0005-7967(94)00075-U

Meerkerk, G. J., Eijnden, V. D., Vermulst, A. A., \& Garretsen, H. F. (2009). The compulsive internet use scale (CIUS): Some psychometric properties. Cyberpsychology and Behaviour, 12(1), 1-6. doi: 10.1089/cpb.2008.0181.

Mihajlov, M., \& Mejmelka, L. (2017). Internet addiction: A review of the first twenty years. Psychiatria Danubina, 29(3), 260-272. doi: 10.24869/psyd.2017.260

Morahan-Martin, J., \& Schumacker, P. (2000). Incidence and correlates of pathological internet use among university students. Computers in Human Behavior, 16(1), 13-29. doi: 10.1016/S0747-5632(99)00049-7

Odaci, H., \& Cikrikci, O. (2017). An exploration of the associations among internet use, depression, anxiety and stress among youths. Mediterranean Journal of Clinical Psychology MJCP, 5(3), 1-13. doi:10.6092/2282-1619/201.5.1635

Pais-Ribeiro, J. L., Honrado, A., \& Leal, I. (2004). Contribuição para o estudo da adaptação portuguesa das escalas de ansiedade, depressão e stress (EADS) de 21 itens de Lovibond e Lovibond. Psicologia, Saúde \& Doenças, 5(2), 229-239. Retrieved from $\quad<$ http://www.scielo.mec.pt/scielo. php?script=sci_arttext\&pid=S1645-00862004000200007\&ln $\mathrm{g}=\mathrm{pt \& nrm}=\mathrm{iso}>$. ISSN 1645-0086.

Patrão, I. M., Rita, J. S., \& Pontes, H. M. (2013). Internet addiction and loneliness among Portuguese elementary school students: An exploratory quantitative study. Atencion Primaria, 45(2), 132-188. doi: 10.1016/S0212-6567(13)70034-9.

Poli, R., \& Agrimi, E. (2012). Internet addiction disorder: Prevalence in an Italian student population. Nordic Journal of Psychiatry, 66(1), 55-59. doi: 10.3109/08039488.2011.605169.

Pontes, H. M., Caplan, S. E., \& Griffiths, M. D. (2016). Psychometric validation of the Generalized Problematic Internet Use Scale 2 in a Portuguese sample. Computers in Human Behavior, 63, 823-833. doi:10.1016/j.chb.2016.06.015

Pontes, H. M., Patrão, I. M., \& Griffiths, M. D. (2014). Portuguese validation of the internet addiction test: An empirical study. Journal of Behavioural Addictions, 3(2), 107-114. doi: 10.1556/JBA.3.2014.2.4
Pontes, H. M., \& Griffiths, M. D. (2016). Portuguese validation of the internet gaming disorder scale short-form. Cyberpsychology, Behavior and Social Networking, 19(4), 1-6. doi: 10.1089/cyber.2015.0605

Rumpft, H. J., Vermulst, A. A., Bischof, A., Kastirke, N., Guertler, D., Bischof, G., ... Meyer, C. (2014). Occurrence of Internet addiction in a general population sample: A latent class analysis. European Addiction Research, 20(4), 159-166. doi: $10.1159 / 000354321$

Smahel, D., Vondrácková, P., Blinka, L., \& Godoy-Etcheverry, S. (2009). Comparing addictive behaviour on the internet in the Czech Republic, Chile and Sweden. In G. Cardosso, A., Cheong, \& J. Cole (Eds.). World wide internet: Changing societies, economies and cultures (pp.544-582). Macao: University of Macao.

Starcevic, V. (2013). Is Internet addiction a useful concept? Australian and New Zealand Journal of Psychiatry, 47(1), 1619. doi: $10.1177 / 0004867412461693$

Tokunaga, R. S. (2015a). A unique problem or the manifestation of a pre-existing disorder? The mediating role of problematic internet use in the relationships between psychosocial problems and functional impairment. Communication Research, 41(4), 531-560. doi: 10.1177/0093650212450910

Tokunaga, R. S. (2015b). Perspectives on internet addiction, problematic internet use, and deficient self-regulation: Contributions of communication research. Annals of the International Communication Association, 39(19), 131-161. doi: 10.1080/23808985.2015.11679174

Tokunaga, R. S., \& Rains, S. A. (2016). A review and metaanalysis examining conceptual and operational definitions of problematic internet use. Human Communication Research, 42(2), 165-199. doi:10.1111/hcre.12075.

van den Eijenden, R. J., Meerkerk, G. J., Vermulst, A. A., Spijkerman, R., \& Engels, R. C. (2008). Online communication, compulsive internet use, psychosocial well-being among adolescents: A longitudinal study. Development Psychology, 44(3), 655-665. doi:10.1037/0012-1649.44.3.6.655

Vigna-Taglianti, F., Brambilla, R., Priotto, B., Angelino, R., Cuomo G., \& Diecidue, R. (2017). Problematic internet use among high school students: Prevalence, associated factors and sex differences. Psychiatric Research, 257, 163-171. doi: 10.1016/j.psychres.2017.07039

Vondrácková, P., \& Gabrhelík, R. (2016). Prevention of internet addiction: A systematic review. Journal of Behavioral Addictions, 5(4), 568-579. doi:10.1556/2006.5.2016.085

Weinstein, A., Doarni, D., Elhadif, R., Bukozva, Y., \& Yarmulnik, A. (2015). Internet addiction is associated with social anxiety in young adults. Annals of Clinical Psychiatry, 27(1), 2-7. doi: $10.1093 / \mathrm{med} / 9780199380183.003 .0001$

World Health Organization (2019). ICD-11 for mortality and morbidity statistics (version 04/2019). Retrieved from https:// icd.who.int/browse 11/1-m/en\#/http://id.who.int/icd/ entity/338347362

Young, K. (1999). Internet addiction: symptoms, evaluation and treatment. In L. C. Vande, \& T. Jackson (Eds.). Innovations in clinical practice (pp.19-31). Sarasota: Professional Resource Press. 
